\title{
ASPECTOS DA ECOLOGIA E DA REPRODUÇĀO DE Leptinaria unilamellata (ORBIGNY, 1835) (GASTROPODA, SUBULINIDAE).
}

\author{
Ana Virginia Calógeras Dutra ${ }^{1}$
}

\begin{abstract}
Leptinaria unilamellata is a species of veterinary importance, being cited here in Pernambuco for the first time. Accounts of both environment and reproduction are made. Ecological observations in a population of Dois Irmãos, Recife, Pernambuco, show predominance in relation to the sympatric snail: Bulimulus tenuissimus, Subulina octona and Sarasinula sp., and showed exceptional ability to adapt to environmental conditions.

From August 1982 to November 1983 a total of 1.169 specimens were collected and classified into 8 class sizes. The average occurences in each month indicate that the population is in a state of reproductive equilibrium. Sexual maturity begins at a body length of $6.1-7.0 \mathrm{~mm}$, when the specimens (still at half their final lenght) already manifest embryos in the uterus, numbering 1 to 8 .
\end{abstract}

\section{INTRODUÇÃO}

Leptinaria unilamellata participa do ciclo evolutivo de Postharmostomum gallinum, parasita de aves, abrigando a forma infectante e constituindo-se no segundo hospedeiro intermediário facultativo. Considerada atualmente espécie cosmopolita, tem sua distribuição ampliada principalmente por ação antrópica. Araújo (1982) cita sua ocorrência no Brasil em: Mato Grosso, Amazonas, Roraima, Minas Gerais, Bahia, Rio de Janeiro, São Paulo e Paraná. Assinalada agora em Pernambuco, foi encontrada também quer em ambiente de fitosionomia de mata, como os brejos de Taquaritinga do Norte (Serra do Taquara) e Caruarú (Serra dos Cavalos), quer em áreas urbanas e jardins de residências em Recife (Dutra, não publicado).

Pilsbry, $1906 \mathrm{diz}$ serem as espécies de Leptinaria de difícil e crítica diagnose por apresentarem grande variação conquiliológica, com extremos conectados por formas intermediárias. Ressalta que só com a realização de estudos com boas séries de jovens a adultos ficariam determináveis as espécies.

L. unilamellata apresenta peristômio simples, lamela parietal e columela truncada desde o embrião; não dando assim indicativo conquiliológico externo

1 Departamento de Zoologia, Universidade Federal de Pernambuco. Cidade Universitária, 50.000 - Recife - PE. 
Revta bras. Zool.

do seu grau de desenvolvimento. Muitas vezes, exemplares jovens foram confundidos com outras espécies de Subulininae, pela grande convergência apresentada nos caracteres da concha e seleção de nichos ecológicos. Araújo (1982) cita uma constante simpatria dessa espécie com espécies de Opeas e com Subulina octona. Notando que é uma espécie pouco estudada, assinala sua participação no ciclo evolutivo de $P$. gallinum, além de apresentar a anatomia do aparelho reprodutor e da cavidade do manto.

Este estudo visa contribuir com o conhecimento da biologia de L. unilamellata, enfocando observações sobre a ecologia, tamanho da maturidade sexual, ciclo de vida e processo reprodutivo. Fornecendo, deste modo, subsídios a medidas de controle que porventura venham a se fazerem necessárias. Apresenta também, as variações conquiliológicas da população, a fim de ser obtida uma melhor identificação para L. unilamellata e porventura clarear o posicionamento sistemático de outras espécies próximas.

\section{MATERIAL E MÉTODOS}

Os 1.169 exemplares estudados neste trabalho foram coletados entre agosto de 1982 e novembro de 1983, em coletas mensais (Tab. 1), em área do Campus da Universidade Federal Rural de Pernambuco, Recife-PE. Consiste em área de cobertura vegetal erbácea, com $359,538 \mathrm{~m}^{2}$, onde predominam gramíneas, ciperáceas e uma composta da espécie Wadelia palulosa (L). Situada às margens do Rio Camaragibe, acha-se delimitada lateralmente por pequenos trechos de cultura de subsistência. O dimensionamento desta área foi efetuado pelo método das mesas, segundo Welch, 1948.

Com o objetivo de avaliar a densidade e distribuição da fauna de moluscos associada, foi utilizado o método de subregiões (9 quadrados de $1 \mathrm{~m}^{2}$ lançados ao acaso) quando da primeira coleta, em agosto de 1982 . Sendo possível então a observação da distribuição instantânea da malacofauna presente nessa área. As coletas seguintes, de setembro de 1982 a novembro de 1983 foram feitas ao acaso e realizadas entre 6 e 8 horas da manhã. Em setembro e novembro de 1982 e em janeiro e agosto de 1983 foram retirados números de exemplares prefixados, por classe de comprimento, o que não permitiu a inclusão destas em histogramas de frequência (fig. 1).

A estimativa do índice de agregação (Ia) e cálculo da densidade média seguem Santos (1978). Calculados os valores de Ia aplicou-se o teste de hipótese de Thomas (1951), apud Santos (1978).

Os exemplares coletados foram anestesiados colocando-os em vidros fechados plenos de água, no refrigerador, por 2 a 5 dias. Separados em 8 classes de comprimento, foram fixados no Bouin para estudos histológicos e no álcool $70^{\circ}$ glicerinado para observações anatômicas, sob microscópio.

Espécimes adultos tiveram suas conhas medidas quanto ao: comprimento total, diâmetro maior, diâmetro menor utilizando-se um paquímetro e contadas o número de voltas, sob microscópio. 
Vol. 5(4), 1988
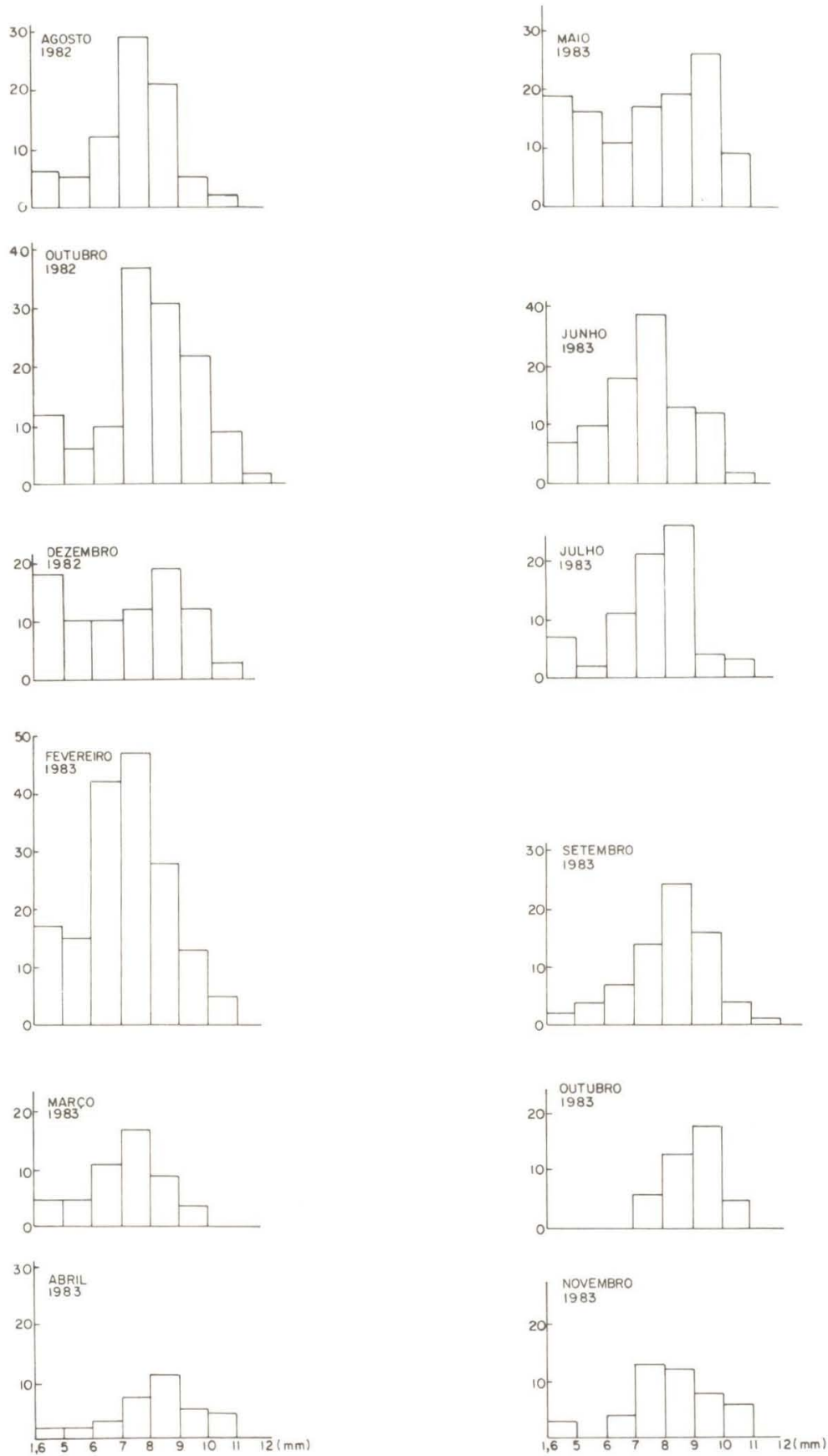

FIG. 1 - Histograma de freqüência mostrando distribuição de comprimento por meses de coleta de Leptinaria unilamellata. 
Revta bras. Zool.

\section{RESULTADOS}

\section{Ecologia}

$\mathrm{Na}$ área estudada, L. unilamellata (fig. 3) ocorre junto com Bulimulus tenuissimus (Orbigny, 1835) e Sarasinula sp.. Tendo-se encontrado, raramente, exemplares de Subulina octona (Bruguière, 1792).

Com a utilização do método de subregiões, em agosto de 1982 foram encontrados: 107 exemplares de L. unilamellata, 11 de Sarasinula sp. e 8 de Bulimulus tenuissimus.

L. Unilamellata habita o solo, sobre e sob talos e folhas decaídas. Ainda no solo, se oculta abaixo de entrelaçado de ramos de gramíneas secas e raízes de ervas que chegam a ter até $15 \mathrm{~cm}$ de espessura. Assim oculta, evita a incidência direta do sol e consequente ressecamento. Nos meses mais quentes era alí que a encontrávamos.

Bulimulus tenuissimus ocorre verticalmente nos ramos e talos das ervas; eventualmente encontrados no solo, em locomoção sobre talos e folhas de ervas caídas.

Sarasinula sp. se encontra no solo, em talos de ervas decaídas e amareladas. Também junto com $L$. Unilamellata, abaixo da camada de ramos e raízes entrelaçadas que atapetam o solo.

Exemplares de Subulina octona foram encontrados no solo e também abaixo do entrelaçado de ramos e raízes sobre o solo.

Em abril de 1983 parte da área foi capinada para expansão do plantio de mandioca, permanecendo intacta área de aproximadamente $22 \mathrm{~m}^{2}$, onde foram feitas as coletas deste mês e do mês seguinte. Tendo-se evitado o plantio acima referido, foi notado em maio, a expansão da composta $W$. paludosa; em junho também da gramínea e em julho e área anteriormente alterada já estava restabelecida.

\section{Estrutura Espacial}

Foi determinada a distribuição espacial instantânea da malacofauna em agosto de 1982 (tab. 2). De acordo com os resultados obtidos na tab.2, L. unilamellata apresentou distribuição agregada (Ia $>1) ; B$. tenuissimus, distribuição uniforme (Ia $<1$ ), o mesmo ocorrendo com Sarasinula sp.. Não foi observada a distribuição espacial para Subulina octona pela mesma não ter sido representada na amostragem de agosto de 1982.

\section{Densidade}

Estimada a densidade média de indivíduos, em agosto de 1982 em 9 subregiões (quadrados), foi obtido valor médio de 11,88 indivíduos por $\mathrm{m}^{2}$ para L. unilamellata; extrapolando-se para a área total resulta em 4.274 individuos. Para $B$. tenuissimus, 0,88 indivíduos por $\mathrm{m}^{2}$ e 319 para a área total. 
Vol. 5(4), 1988

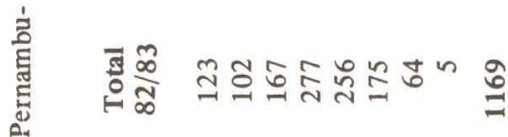

ซ

荧

\#兽 $0006 m \infty n 0$ N

若离

路

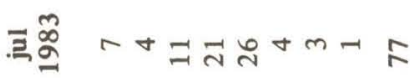

동

ह 於

E

号 न气

¿

匈

㤩 㤩

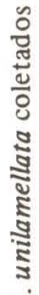

สू a a a a

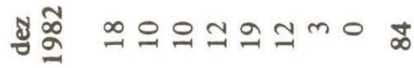

융 $\infty \infty \infty \infty \infty \infty \sim \circ$

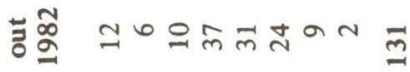

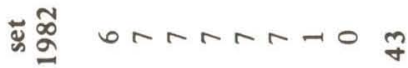

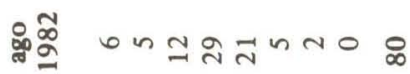

E⿶凵 0.000000

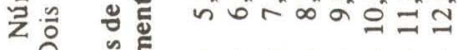

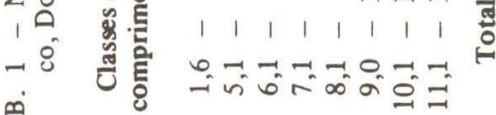

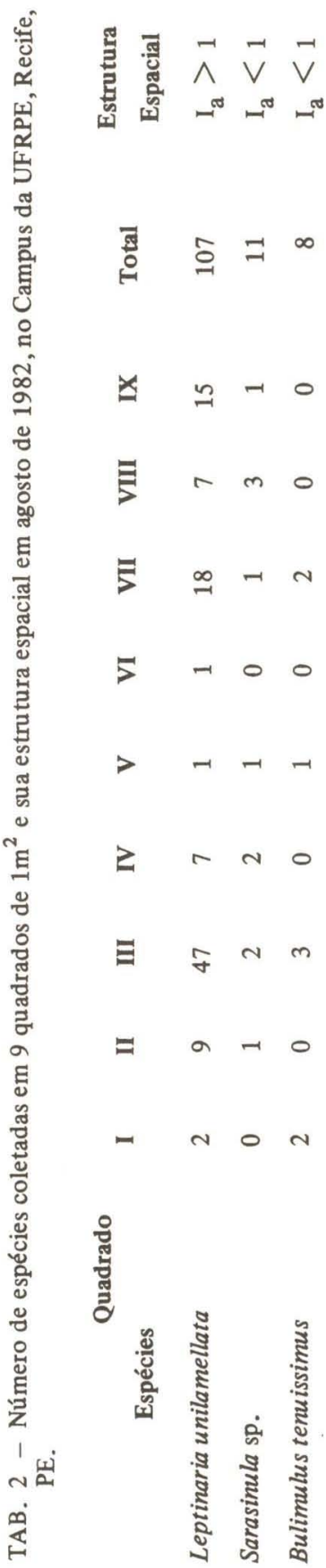


Revta bras. Zool.

Para Sarasinula sp., 1,22 indivíduos por $\mathrm{m}^{2}$ e 439 indivíduos para toda a área amostrada.

\section{Ciclo de Vida e Reprodução}

Os exemplares coletados foram incluídos em oito classes de comprimento. A primerra tem limite inferior a $1,6 \mathrm{~mm}$ por ter sido este o menor tamanho encontrado entre os recém-nascidos.

A distribuição de freqüências de comprimento para cada mês de coleta foi apresentada por histograma de freqüências (fig. 1). Este histograma caracteriza-se notadamente por uma distribuição unimodal, não havendo distinção de classes etárias. Analisando-se esta figura observa-se que a maior amplitude da variável comprimento ocorreu nos meses de outubro de 1982 a setembro de 1983, quando foram obtidos representantes das oito classes de comprimento. Nos meses de dezembro de 1982 e fevereiro e maio de 1983 ocorreu número significativo de jovens da menor classe de comprimento: de 1,6 a $5,0 \mathrm{~mm}$, quando chegam a perfazer quase mais uma moda, e contribuindo para uma queda no comprimento médio dos indivíduos ao longo do tempo (fig. 2). Nos demais meses o histograma segue aproximadamente uma curva normal. $\mathrm{O}$ achatamento do histograma na freqüência de indivíduos em abril de 1983 deveu-se à redução da área de coleta devido a alterações ocorridas e já reportadas.

O gráfico da figura 2, do comprimento médio dos indivíduos em função das datas de coletas, mostra distribuição de classes de comprimento quase uniformes ao longo dos meses de coleta, dando indicativo de que a população se reproduz continuamente ao longo do tempo. A média apresentou valor de $7,65 \mathrm{~mm}$ a moda de $7,50 \mathrm{~mm}$, ambas muito próximas. Indicando, assim que a reprodução ocorreu em todo o período de estudos. Contudo, há indicativo de período de maior liberação de jovens. Em abril e outubro observou-se um leve aumento no comprimento médio dos indivíduos (fig. 2), devido também a pouca freqüência de jovens de até $6,0 \mathrm{~mm}$. Podendo-se crer ocorrer em torno destes períodos uma maior atividade de reprodução resultando numa maior liberação de jovens nos meses respectivamente seguintes, em maio e dezembro (fig. 1). Aliado ao fato de que são os indivíduos de maior comprimento os responsáveis pela reprodução de maior número de embriões (tab. 3). Os espécimes aqui estudados, em número de 1.169 , chegam a atingir um comprimento máximo de $12 \mathrm{~mm}$, diâmetro de $5,8 \mathrm{~mm}$ e 6,5 voltas da concha (tab. 4).

Análises anatômicas na genitália de 498 exemplares, coletados mensalmente, constatam a presença de embriões no útero a partir de exemplares da classe de comprimento de 6,1 a 7,0 mm (tab. 3). Sendo então considerados adultos.

Ovos e embriões em vários estágios de desenvolvimento foram encontrados no útero intumescido e expandido (figs. 4 - 6). Os ovos são arredondados e flexíveis, envolto em membrana não calcificada como em Pseudopeas, não apresentando casca calcárea como $S$. octona. Os embriōes têm distribuição linear no útero quando em número reduzido. Quando um maior número podem ocorrer em filas paralelas ou alternadamente. Em número, variam de 1 a 8 (tab. 3). As vezes se apresentam em diferentes estágios de desenvolvimento, estando o mais maduro, geralmente, mais próximo à borda do manto. 
Vol. 5(4), 1988

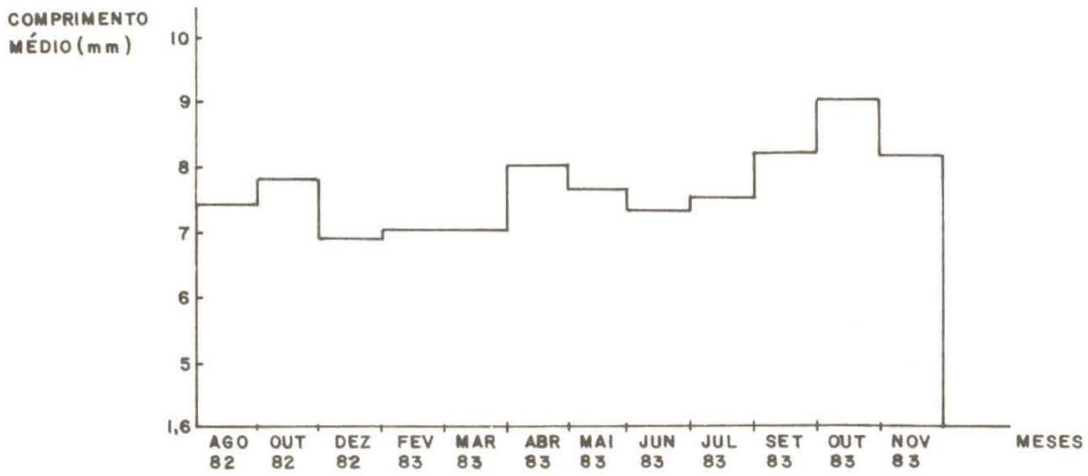

FIG. 2 - Gráfico mostrando o comprimento médio dos indivíduos de L. unilamellata ao longo dos meses de coleta.

TAB. 3 - Relação entre o comprimento e o número de embriões em L. unilamellata, coletados de agosto/1982 a novembro/1983.

\section{Classes de} comprimento $(\mathrm{mm})$

$1,6-5,0$

$5,1-6,0$

$6,1-7,0$

$7,1-8,0$

$8,1-9,0$

$9,1-10,0$

$10,1-11,0$

$11,1-12,0$

Total

\section{Número de indivíduos}

46

60

76

89

92

84

48

3

498

\section{Com} embriōes

0
0
18
51
77
60
30
1

237

\section{Amplitude de variação do número de embriões}

\section{Sem embriões}

46
60
58
38
15
24
18
2

261

TAB. 4 - Medidas coquiliológicas $(\mathrm{mm})$ de 125 exemplares adultos de L. unilamellata, do Campus da Universidade Federal Rural de Pernambuco, Recife, PE.

\section{Parâmetros conquiliológicos}

Comprimento total

Diâme tro maior

Diâmetro menor

Número de voltas

\section{$\overline{\mathbf{X}}$}

8,25

4,36

4,11

5,35
Sd

1,38

0,51

0,62

0,51
Amplitude de variação 
Revta bras. Zool.
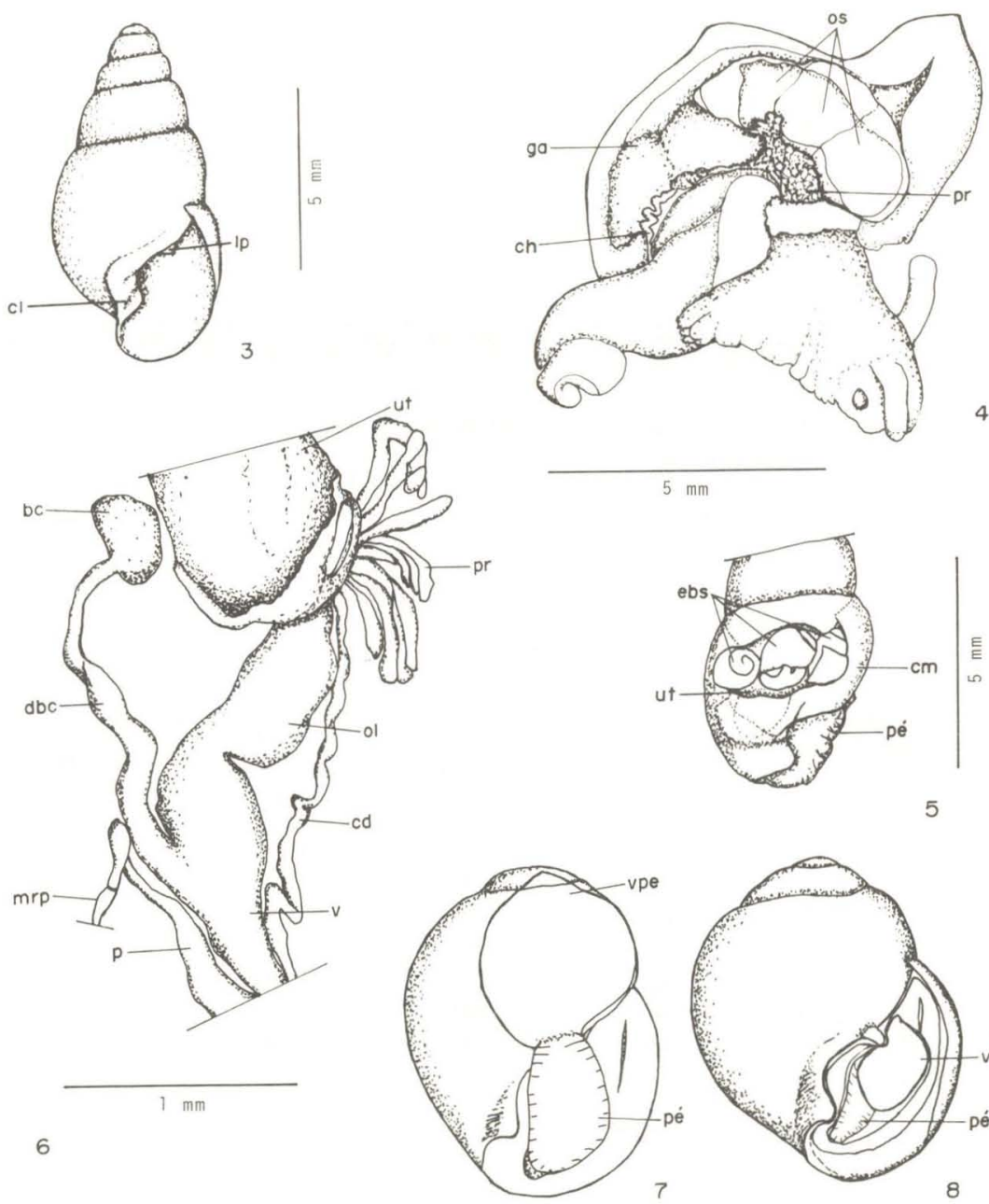

4

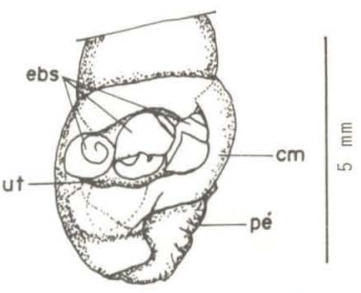

5

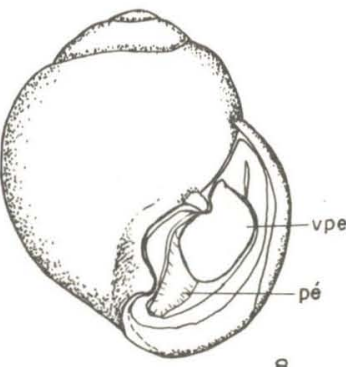

$1 \mathrm{~mm}$

FIGS. 3-8 - L. unilamellata. 3, concha. Cl, columela; lp, lamela parietal. 4, ovos no útero (exemplar parcialmente dissecado). Ch, canal hermafrodita; ga, glândula de albumina; os, ovos; pr, próstata. 5, disposição de embriōes já desenvolvidos no útero. $\mathrm{Cm}$, cavidade do manto; ebs, embriões; ut, útero. 6, porção expandida do útero após a retirada de embriões. Bc, bursa copulatrix; cd, canal deferente; dbc, ducto da bursa copulatrix; mrp, músculo retrator peniano; ol, oviduto livre; p, pênis; pr, próstata; ut, útero; v, vagina. 7 e 8 , embriões já desenvolvidos, sem a membrana envoltória, com graus de desenvolvimento variados do pé e da vesícula pediosa. Vpe, vesícula pediosa. 
Vol. 5(4), 1988

Os embriões desenvolvem-se consumindo todo o vitelo. Quando estão com a concha embrionária completamente formada, ocupam o espaço delimitado pela membrana envolvente, muito tênue e transparente, que lhes adere. Alguns não apresentavam esta membrana, parecendo ter sido a mesma reabsorvida. Nestes embriões já desenvolvidos a vesícula pediosa ocorre em diferentes graus de desenvolvimento (figs. 7 e 8 ).

Os jovens nascem em média com 1,6 a 2,3 mm de comprimento, 2,2 a 2,5 voltas. Apresentam lamela parietal e columela truncada. Muitas das vezes ocorreu liberação de jovens no transporte dos exemplares ao laboratório, quando já saem prontos, em livre locomoção.

\section{DISCUSSÃO}

Araújo (1982) observa que, sob o ponto de vista médico veterinário, os moluscos hospedeiros de parasitas exibem exigências ambientais: encontrar os parasitas que deles dependem para desenvolver seus ciclos, freqüentemente até a forma infectante para o hospedeiro definitivo. O ambiente estudado no Campus da Universidade Federal Rural de Pernambuco é uma área totalmente aberta, conectada com o rio por onde transitam bovinos, equinos, cães e aves. Muitas das vezes foram encontradas fezes de bovinos e equinos, o que permitiria estabelecimento de ciclos evolutivos para outros parasitas que não apenas o $P$. gallinum de aves. Como cita o mesmo Araújo, esta espécie pode ser hospedeira potencial de Eurytrema coelomaticum de bovinos e caprinos. Parasita ainda não citado para Pernambuco, ocorrendo junto com L. unilamellata no Rio de Janeiro, Minas Gerais, São Paulo e Mato Grosso.

L. unilamellata povoa densamente a área, tendo dominado ao longo do tempo as espécies associadas: Bulimulus tenuissimus, Sarasinula sp. e Subulina octona. Seu sucesso pode estar associado a uma grande capacidade de absorver alimento do ambiente aliado a não concorrência com competidores fortes (de grande potencial reprodutivo) como $S$. octona, pouco freqente na área estudada. Talvez porque esta espécie tenha penetrado na área estudada apenas recentemente.

Foi encontrado, em todo o período de estudos, um número reduzido de jovens com até $5,0 \mathrm{~mm}$ de comprimento. Sendo menos conspícuos, talvez não tenham sido vistos e coletados. Talvez diferenças na drenagem do substrato e na vegetação (o que influencia a alimentação e umidificação) resulte numa taxa diferencial de mortalidade entre jovens e adultos, nas estações chuvosas e não chuvosas. $\mathrm{Na}$ última classe de comprimento $(11,1-12,0 \mathrm{~mm})$ figuram igualmente poucos exemplares; indicando longevidade curta.

$\mathrm{Na}$ população aqui analisada, a reprodução inicia-se cedo, quando os exemplares atingem a metade de seu comprimento total $(6,1-7,0 \mathrm{~mm})$. Dissecações efe tuadas mostram que nesta classe de comprimento os indivíduos têm o sistema reprodutor desenvolvido e também funcional (já com embriões no útero). Sendo possível que a necessidade de uma reprodução iniciada cedo seja estratégica para a colonização de ambientes com substrato restrito. 
A presença e o número de embriões no útero foi uma das informações biologicas utilizadas para verificar o grau de maturidade e a produção de $L$. unilamellata ao longo do período de estudos. Sendo a classe de maior produção a de 8,1 a $9,0 \mathrm{~mm}$, seguida pelas de $9,1-10,0 \mathrm{~mm}$ e de $7,1-8,0 \mathrm{~mm}$ (tab. 3). Na classe de comprimento em que se inicia a reprodução, $(6,1-7,0 \mathrm{~mm})$, nota-se que o número de embriões oscila entre 1 e 4 . Parecendo que estes exemplares menores não conseguem fecundar e formar um maior número de embriōes, provavelmente devido ao limite de espaço do próprio útero que pressionaria a cavidade do manto, não muito grande.

Os embriões em fase próxima à liberação do organismo materno apresentam algumas variações. Inicialmente acham-se envolvidos pela membrana vitelina, muito fina e transparente. Parecendo perdê-la numa fase muito próxima a serem liberados. Fato indicado pelo encontro de embriões com ou sem membranas, no útero de organismos distintos, com aproximadamente o mesmo tamanho e igual número de voltas da concha embrionária. Marcus \& Marcus (1968), no estudo sobre os subulinídeos de São Paulo, dizem que nestes, a casca calcárea do ovo e a casca membranosa são reabsorvidas no útero e que pode ocorrer liberação dos últimos embriões, no ambiente, ainda com casca. Podendo ocorrer o mesmo com $L$. unilamellata em relação à membrana do embrião. Um outro caráter notado foi a presença de uma vesícula ligada ao pé, mais ou menos desenvolvida, como se observa nas figs. 7 e 8 . Raven (1975) diz que esta vesícula tem poder de contração, podendo aumentar em embriões maduros. Assim, poderia funcionar como auxiliar na retirada de nutrientes do fluido uterino. Provavelmente com a mesma finalidade, um maior desenvolvimento do pé, notado em alguns embriões.

Leme (1980) observa que a conceituação de viviparidade e ovoviviparidade em moluscos é assunto controverso, e com pouquíssimos dados conclusivos. Mackie (1978) discute estes conceitos, cujas definições diferem quanto a localização do desenvolvimento do embrião (se no aparelho reprodutor ou fora dele) e na origem do nutriente e meio de obtê-lo pelo embrião. Cita que apenas Abercrombie et al. (1977) adicionou outro critério: a presença ou não de membrana vitelina. Dentre as definições de viviparidade há uma concordância de que ocorra uma ligação direta do embrião com o organismo materno para fins nutricionais. Marcus \& Marcus (1968) conceituam todos os subulinídeos estudados como vivíparos, apesar de não analisar, em todos, a existência de uma possível ligação direta dos embriões com o organismo materno para alimentação.

A espécie aqui estudada apresenta caracteres que levam a conceituá-la como vivípara ou ovovivípara, de acordo com as definições existentes. Apresenta uma membrana vitelina em quase todo seu desenvolvimento; os embriões se localizam no sistema reprodutor (dentro do útero); ocorre arranjo anatômico especial para absorver nutrientes (vesícula pediosa e desenvolvimento do pé). Contudo, a não observação de uma ligação anatômica direta com o organismo materno, para alimentação, sem passar pelo estágio intermediário de absorver nutrientes dissolvidos no fluido uterino, levam a conceituar $L$. unilamellata como espécie ovovivípara, incluida no estágio intermediário à viviparidade. 
Vol. 5(4), 1988

\section{AGRADECIMENTOS}

Ao Prof. Dr. José Willibaldo Thomé, Presidente da Fundação Zoobotânica do Rio Grande do Sul, Porto Alegre, RS, pela revisão do trabalho. Ao Prof. Antônio Lisboa Nogueira da Silva da UFRPE, pelo auxilio no tratamento dos dados estatísticos. À estagiária Mariléia Barbosa e Sr. José Carlos Galvão pelo auxilio nos trabalhos de campo.

\section{REFERENCIAS}

Araújo, J.L.B. 1982. Alguns moluscos terrestres como hospedeiros intermediários de parasitas de animais domésticos, no Brasil: estudos sobre a anatomia, sistemática e participação em helmintoses. Itaguaí, 103pp. Tese de Doutorado, Universidade Federal Rural do Rio de Janeiro.

Gardiner, MS. 1972. The Biology of Invertebrates, Mc Graw Hill Book Co., New York, $954 \mathrm{pp}$.

Mackie, G.L. 1978. Are Sphaeriid clams ovoviviparous or viviparous? The Nautilus 92(4): $145-147$.

Marcus, E. \& E. Marcus. 1968. Uber einige Subulinidae (Pulmonata von São Paulo). Beitr. neotrop. Fauna, 5:186-208.

Leme, J.L.M. 1980. Viviparidade em Tomigerus (Gastropoda, Bulimulidae) com a descrição de uma nova espécie. Papéis Avulsos Zool. São Paulo, 23(25):355-363.

Pilsbry, H.A. 1906. Manual of Conchology, vol. XVIII 284-294, pls. 42 e 43. Philadelphia, PA.

Raven, C.P. 1975. Development. In: Fretter, V. \& Peake J. Pulmonates: 1:367-400. Academic Press, London.

Santos, E.P. 1978. Dinâmica de populações aplicadas à pesca e piscicultura. Ed. Hucitec - Universidade de São Paulo, São Paulo.

Welch, T.S. 1948. Limnological Methods. Blakiston Co., Philadelphia, PA; 381 pp. 